Correction

\title{
Correction: Garthwaite, M.C. on the Design of Radar Corner Reflectors for Deformation Monitoring in Multi-Frequency InSAR. Remote Sens. 2017, 9, 648
}

\author{
Matthew C. Garthwaite \\ Geodesy and Seismic Monitoring Branch, Geoscience Australia, GPO Box 378, Canberra ACT 2601, Australia; \\ Matt.Garthwaite@ga.gov.au
}

Received: 8 January 2018; Accepted: 9 January 2018; Published: 10 January 2018

After publication of the research paper [1], the author wishes to make the following correction to the paper. In the original paper, the relationship between SCR and LOS displacement error (plotted in Figure 3) was in error for the C and L-band. Updating the required SCR for C and L-band impacts the required RCS for artificial targets and the equivalent triangular trihedral corner reflector size (both listed in Table 1). In this corrected version of the paper, Figures 3 and 4 and Table 1 have been updated to correct this error, and some modifications to the text in Section 2 (Theoretical Considerations) have been made. The experimental results presented and the overall conclusions of the paper are not affected by these changes. The original manuscript [1] has been updated with these changes. We apologize for any inconvenience caused by this mistake.

\section{Reference}

1. Garthwaite, M.C. On the Design of Radar Corner Reflectors for Deformation Monitoring in Multi-Frequency InSAR. Remote Sens. 2017, 9, 648. [CrossRef]

(C) 2018 by the author. Licensee MDPI, Basel, Switzerland. This article is an open access article distributed under the terms and conditions of the Creative Commons Attribution (CC BY) license (http://creativecommons.org/licenses/by/4.0/). 